\title{
RESEARCH
}

Open Access

\section{High-efficiency derivation of human embryonic stem cell lines using a culture system with minimized trophoblast cell proliferation}

Chuti Laowtammathron ${ }^{1}$, Pimjai Chingsuwanrote ${ }^{1}$, Roungsin Choavaratana ${ }^{2}$, Suphadtra Phornwilardsiri ${ }^{2}$, Ketsara Sitthirit ${ }^{2}$, Chidchanok Kaewjunun ${ }^{2}$, Orawan Makemaharn², Papussorn Terbto ${ }^{3}$, Supaporn Waeteekul ${ }^{4}$, Chanchao Lorthongpanich ${ }^{1}$, Yaowalak U-pratya ${ }^{1,5}$, Pimonwan Srisook ${ }^{1}$, Pakpoom Kheolamai ${ }^{1,6}$ and Surapol Issaragrisil ${ }^{1,5^{*}}$

\begin{abstract}
Background: Due to their extensive self-renewal and multilineage differentiation capacity, human embryonic stem cells (hESCs) have great potential for studying developmental biology, disease modeling, and developing cell replacement therapy. The first hESC line was generated in 1998 by culturing inner cell mass (ICM) cells isolated from human blastocysts using an immunosurgery technique. Since then, many techniques including mechanical ICM isolation, laser dissection, and whole embryo culture have been used to derive hESC lines. However, the hESC derivation efficiency remains low, usually less than $50 \%$, and it requires a large number of human embryos to derive a significant number of hESC lines. Due to a shortage of and restricted access to human embryos, a novel approach with better hESC derivation efficiency is badly needed to decrease the number of embryos used.

Methods: We hypothesized that the low hESC derivation efficiency might be due to extensive proliferation of trophoblast (TE) cells which could interfere with ICM proliferation. We therefore developed a methodology to minimize TE cell proliferation by culturing ICM in a feeder-free system for 3 days before transferring them onto feeder cells.

Results: This minimized trophoblast cell proliferation (MTP) technique could be successfully used to derive hESCs from normal, abnormal, and frozen-thawed embryos with better derivation efficiency of more than 50\% (range 50-100\%; median 70\%).

Conclusions: We successfully developed a better hESC derivation methodology using the "MTP" culture system. This methodology can be effectively used to derive hESCs from both normal and abnormal embryos under feeder-free conditions with higher efficiency when compared with other methodologies. With this methodology, large-scale production of clinical-grade hESCs is feasible.
\end{abstract}

Keywords: Human embryonic stem cells, Embryo, Clinical grade, Trophoblast cells

\footnotetext{
* Correspondence: surapolsi@gmail.com

${ }^{1}$ Siriraj Center of Excellence for Stem Cell Research (SiSCR), Faculty of

Medicine Siriraj Hospital, Mahidol University, Bangkok 10700, Thailand

${ }^{5}$ Division of Hematology, Department of Medicine, Faculty of Medicine Siriraj

Hospital, Mahidol University, Bangkok 10700, Thailand

Full list of author information is available at the end of the article
}

(c) The Author(s). 2018 Open Access This article is distributed under the terms of the Creative Commons Attribution 4.0 International License (http://creativecommons.org/licenses/by/4.0/), which permits unrestricted use, distribution, and reproduction in any medium, provided you give appropriate credit to the original author(s) and the source, provide a link to the Creative Commons license, and indicate if changes were made. The Creative Commons Public Domain Dedication waiver (http://creativecommons.org/publicdomain/zero/1.0/) applies to the data made available in this article, unless otherwise stated. 


\section{Background}

Human embryonic stem cells (hESCs) have the capability to self-renew indefinitely in culture while retaining their ability to differentiate to all cell types. hESCs not only play important roles in basic research in developmental biology, disease pathogenesis, and gene function, but also serve as a valuable model for drug screening and tissue transplantation. At present, more than $300 \mathrm{hESC}$ lines have been eligibly registered to the National Institutes of Health Human Embryonic Stem Cell Registration (http://grants.nih.gov/stem_cells/ registry/current.htm). Most hESCs are usually derived from discarded embryos or embryos donated from a couple who have completed in vitro fertilization (IVF) treatments and have no desire to utilize the remaining embryos for transplantation [1, 2]. To generate hESC lines for various research and clinical applications, a large number of human embryos are usually required (Additional file 1: Table S1) [2, 3]. To derive hESCs, immunosurgery, mechanical ICM dissection (MID), and whole embryo culture (WEC) techniques are developed. Immunosurgery is a method for removing TE cells, the outer cell layer of blastocysts, through complement-dependent antibody cytotoxicity [4]. Because an animal-derived antibody is required for immunosurgery, this technique is therefore unsuitable for deriving clinical-grade hESCs. Exposing hESCs to animal products could increase risks of zoonosis and immune reaction against contaminated nonhuman molecules, such as sialic acid $N$-Glycolylneuraminic acid (Neu5Gc), resulting in the rejection of transplanted hESCs [3, 5-12]. Derivation of hESCs with either MID or WEC can be used to derive clinical-grade hESCs. However, the hESC derivation efficiency with those methods is generally low [1,13-16]. Due to a shortage of and restricted access to human embryos, a more efficient procedure for deriving hESCs under xeno-free conditions is critically needed.

Although induced pluripotent stem cells (iPSCs) generated by epigenetic reprogramming of adult somatic cells can be used as a substitute for hESCs for studying basic biology and pathophysiology of human diseases [17], several recent studies reported that many iPSC lines have acquired various genetic mutations during the course of their generation and expansion that might compromise their clinical use [18-28].

In the present study, we successfully develop better a hESC derivation methodology using a culture system called "minimized trophoblast cell proliferation" (MTP). This methodology can be effectively used to derive hESCs from both normal and abnormal embryos under feeder-free conditions with higher efficiency when compared with other methodologies.

\section{Methods}

\section{Ethical permission for human embryos used}

The study protocol was approved by Siriraj Institutional Review Board, Faculty of Medicine, Siriraj Hospital (SIRB), Mahidol University (Si338/2013). All experiments were performed under the guidelines and regulations of SIRB, Mahidol University. The human embryos used in this study were obtained from the infertility unit, Siriraj Hospital. Informed consent was obtained from all couples that donated spare embryos following in vitro fertilization (IVF) treatment. Before giving consent, the couples were provided with all of the necessary information about the research project and they were made aware of the sensitive nature of the study. Only embryos with genetic abnormalities, diagnosed by performing blastomere biopsy and preimplantation genetic diagnosis (PGD), were used for embryonic stem cell derivation.

\section{Derivation of human embryonic stem cells Whole embryo culture method}

The zona pellucida (ZP) was removed by incubating the embryos with $0.1 \%(\mathrm{w} / \mathrm{v})$ pronase for $5 \mathrm{~min}$ followed by washing in NutriStem medium (Stemgent, USA). The ZP-free embryos were then cultured on human foreskin fibroblasts (HFFs) in NutriStem media under hypoxic conditions (a humidified atmosphere of $5 \% \mathrm{O}_{2}, 5 \% \mathrm{CO}_{2}$, and $90 \% \mathrm{~N}_{2}$ ) (Fig. 1a, b).

\section{Mechanical ICM dissection method}

The ZP-free embryos were transferred to the micromanipulator for ICM isolation. Firstly, the embryos were suspended in a micro-drop of NutriStem medium and their ICMs were adjusted to the 12 o'clock position. A fine glass needle was then pressed on top of the embryos in the region under their ICMs while the holding pipette was placed underneath the needle and moved back and forth several times to tear off TE cells (Fig. 1c). The isolated ICM was then cultured on HFFs in Nutristem medium under hypoxic conditions (Fig. 1a, d).

\section{Minimized trophoblast cell proliferation method}

The ICMs isolated by MID were cultured on plates coated with either CELLstart (Gibco, USA) or Matrigel (Corning, USA) in Nutristem medium under hypoxic conditions. After 3 days of culture, the ICM clump was mechanically separated from the surrounding TE cells and transferred to a fresh culture plate containing HFFs (Fig. 2b). At this stage, half of the culture medium was replaced by fresh medium every day throughout the entire culture period. The culture was observed daily and the cells were mechanically subcultured when their colonies reached optimal size. 

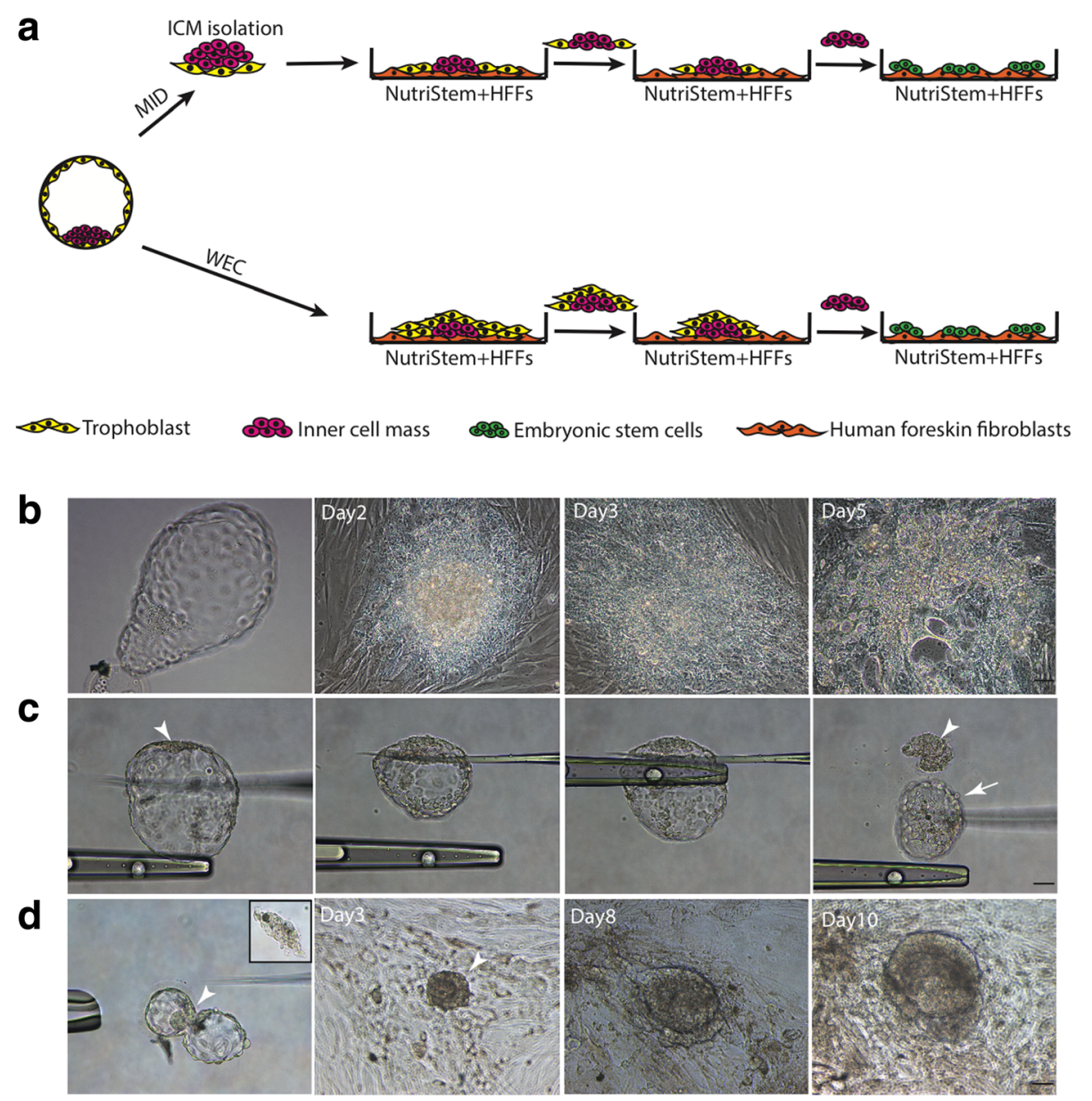

Fig. 1 Derivation of hESCS by WEC and MID. a Process of hESC derivation from human blastocysts by WEC and MID. $\mathbf{b}$ Derivation of hESCs by WEC: culture whole embryo on HFFs without ICM isolation. c, $\mathbf{d}$ ICM (arrowheads) mechanically separated from TE cells (arrow) by glass pipette (c) before transferring onto HFFs for further expansion (d). Scale bar: 50 m. MID: mechanical ICM dissection, ICM: inner cell mass, WEC: whole embryo culture, HFFs: human foreskin fibroblasts

a
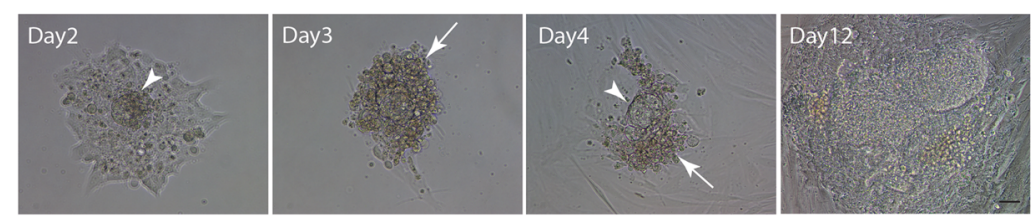

b

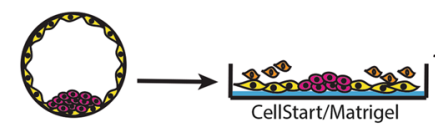

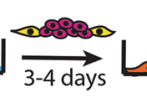

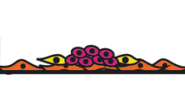

$\infty$ Trophoblasts

@ Inner cell mass

ஊூర Embryonic stem cells

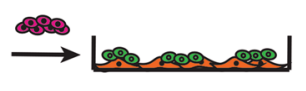

Floating trophoblasts

Fig. 2 Derivation of hESCS by MTP. a On day 2 after ICM isolation, prominent ICM clump (arrowheads) surrounded with proliferating TE cells observed. Under feeder-free conditions using either CELLstart or Matrigel, most proliferating TE cells were degenerated on culture day 3 (arrows) while remaining ICM clump was transferred to fresh HFFs for further expansion. b Procedure of hESC derivation by MTP method. Scale bar: 50 um 


\section{hESC culture}

hESC colonies were cut into small pieces with a fine glass needle and transferred onto freshly prepared gamma-irradiated HFFs. The cells were then cultured in NutriStem medium (Biological Industries, USA) under hypoxic conditions and were subcultured every 4-5 days when their colonies reached optimal size. For the feederfree system, hESC colonies were cultured on a Matrigelcoated plate in NutriStem media under hypoxic conditions and subcultured every 4-5 days using Versene treatment (Life Technologies, USA).

\section{Karyotype analysis}

hESCs were expanded under feeder-free conditions until their density reached $100 \%$ confluence. At this stage, the cells were harvested and sent to Siriraj Central Cytogenetic Laboratory, Faculty of Medicine, Siriraj Hospital, Mahidol University for karyotyping.

\section{Studying the expression of pluripotent marker genes by RT-PCR}

Expression of OCT4, SOX2, and NANOG genes was determined by reverse transcription PCR (RT-PCR). Briefly, total RNA was isolated by Trizol Reagent (Invitrogen, USA), according to the manufacturer's instructions, and $1 \mu \mathrm{g}$ of RNA was converted to cDNA by the RevertAid First Strand cDNA Synthesis Kit (Thermo Scientific, USA). The PCR was then performed and the results were analyzed by agarose gel electrophoresis. The primer sequences are presented in Additional file 1: Table S3.

\section{Immunofluorescence staining}

Cells were fixed with $4 \%(\mathrm{w} / \mathrm{v})$ paraformaldehyde in PBS and their membranes were permeabilized with $0.1 \%(\mathrm{w} / \mathrm{v})$ Triton X-100 in PBS. At this stage, the cells were incubated with $3 \%(\mathrm{w} / \mathrm{v}) \mathrm{BSA}$ in PBS at room temperature for $2 \mathrm{~h}$ to prevent nonspecific antibody reaction before incubating with mouse antibodies against human NANOG (1: 100; Millipore), OCT4 (1:100; Santa Cruz), SOX2 (1:200; Millipore), SSEA4 (1:100; Millipore), TRA1-60 (1:100; Millipore), and TRA-1-81 (1:100; Millipore) at $4{ }^{\circ} \mathrm{C}$ overnight. After incubation with primary antibodies, the cells were washed twice with PBS and further incubated with appropriate secondary antibodies (1:500) at room temperature for $1 \mathrm{~h}$. The nuclei were visualized by staining with Hoechst33342 (Life Technologies, USA) and the cells were studied by fluorescent microscopy.

\section{In vitro differentiation}

hESCs were harvested by incubation with dispase and transferred to low-adherent culture dishes (Corning, USA) containing DMEM (Invitrogen, USA) supplemented with $20 \%(\mathrm{v} / \mathrm{v})$ serum replacement (Invitrogen, USA), $10 \mathrm{mM}$ non-essential amino acids (Invitrogen,
USA), $55 \mathrm{mM} \beta$-mercaptoethanol (Invitrogen, USA), $2 \mathrm{mM} \mathrm{L}$-GlutaMAX (Invitrogen, USA), and $50 \mu \mathrm{g} / \mathrm{ml}$ penicillin/streptomycin (Millipore, USA) to form embryoid bodies (EBs). The medium was replaced every 23 days. On culture day 7, EBs were transferred to gelatin-coated plates and allowed to spontaneously differentiated for a further 2 weeks. The expression of smooth muscle actin (Abcam, USA), $\alpha$-fetoprotein (Calbiochem, USA), and NESTIN (Millipore, USA), markers for three primitive germ layers, was determined by immunofluorescence.

\section{Teratoma formation}

Approximately $1 \times 10^{7} \mathrm{hESCs}$ were suspended in $30 \%$ $(\mathrm{v} / \mathrm{v})$ Matrigel and transplanted intramuscularly into hind legs of 6-8-week-old nude mice. At 8-10 weeks post transplant, the fully formed teratomas were harvested and fixed with $4 \%(\mathrm{w} / \mathrm{v})$ paraformaldehyde in PBS, embedded in paraffin, sectioned, and stained with hematoxylin and eosin for histological analysis.

\section{Detection of a-thalassemia 1 SEA mutation}

Detection of $\alpha$-thalassemia 1 SEA mutation was performed as described previously by Winichagoon et al. [29]. Briefly, one or two blastomeres were removed from the embryos when they reached the eight-cell stage and transferred to a $0.2-\mathrm{ml}$ reaction tube containing $2.5 \mu \mathrm{l}$ lysis buffer and $50 \mu \mathrm{g} / \mathrm{ml}$ proteinase K (Invitrogen, USA). PCR was then performed to detect the mutation of $\alpha$-globin genes. The primer sequences are presented in Additional file 1: Table S3.

\section{Results}

Derivation of hESCs by whole embryo culture and mechanical ICM dissection

To compare the efficiency of our MTP method with previously available hESC derivation methods, we firstly derived hESCs under feeder-based conditions using two standard hESC derivation methods, WEC and MID (Fig. 1a). For WEC, the zona pellucida (ZP) of three human blastocysts was removed by incubating the embryos with pronase enzyme. The zona-free embryos were then cultured on irradiated human foreskin fibroblasts (HFFs) in Nutristem medium, a commercial GMP-certified, xeno-free medium for hESC culture. After 3 days of culture, flattened outgrowths from the embryos were observed (Fig. 1b). However, most of those outgrowths mainly consisted of TE cells which disrupted the ICM organization. On culture day 5, no ICM outgrowth was observed and no hESC line was derived from those three embryos (Fig. 1b and Table 1).

For MID, ICM was mechanically isolated from the surrounding TE cells (Fig. 1c). Six ICM clumps were successfully isolated from six blastocysts (three with $\mathrm{Hb}$ Bart's hydrops fetalis, two with trisomy 13, and one with 
Table 1 Efficiency of hESC derivation using WEC, MID, and MTP techniques ${ }^{a}$

\begin{tabular}{llll}
\hline & Number of embryos $^{\mathrm{b}}$ & Outgrowth (day 3) & Number (\%) of established hESC lines \\
\hline WEC & 3 & 3 & 0 \\
MID & 6 & 6 & $2(33)$ \\
MTP & 10 & 10 & $7(70)$ \\
\hline
\end{tabular}

hESC human embryonic stem cell, WEC whole embryo culture, MID mechanical ICM dissection, ICM inner cell mass, MTP minimized trophoblast proliferation ${ }^{a}$ Experiments presented were performed by the same personnel

${ }^{\mathrm{b}}$ All embryos used were discarded embryos with genetic abnormalities, diagnosed by performing blastomere biopsy and preimplantation genetic diagnosis

trisomy 18). The isolated ICMs were then cultured on irradiated HFFs in Nutristem medium. After 3 days of culture, several distinct ICM organizations surrounded with a small number of TE cells were observed (Fig. 1d). Only two ICMs with $\mathrm{Hb}$ Bart's hydrops fetalis can be further expanded to generate hESC lines, SiBart1 and SiBart2 (Additional file 2: Figure S1).

\section{Decrease TE cell proliferation using a feeder-free culture system}

It is possible that the feeder cells may promote TE cell proliferation which results in the low hESC derivation efficiency observed with the MID technique. We therefore cultured ICMs on plates coated with CELLstart or Matrigel in Nutristem media under hypoxic conditions without feeder cells. We observed that the ICMs attached to both the CELLstart and Matrigel-coated surfaces within the first day and the ICM clumps were prominent after 2 days of culture. Although TE cell proliferation and expansion was initially observed (Fig. 2a), those TE cells subsequently deteriorated on day 3 or 4 . When the ICM clumps were picked and transferred onto fresh HFFs, they further expanded and were ready for passage on culture day 14 while the TE cells were no longer observed. This result indicates that culturing ICMs on CELLstart or Matrigel instead of HFFs can prevent TE cell proliferation and enhance ICM expansion (Fig. 2b).

\section{Enhancement of hESC derivation using the MTP technique} Seven embryos (one parthenogenetic embryo and six aneuploid embryos including two with monosomy 13, two with trisomy 13, one with trisomy 18, and one with XYY syndrome; Fig. 3a) were studied. The ICMs from each embryo were isolated by MID and cultured on Matrigel-coated plates in Nutristem media under hypoxic conditions. On culture day 3, the ICM clumps were separated from the surrounding TE cells and transferred onto HFFs. At this stage, the ICM cells proliferated extensively and five hESC lines were successfully established

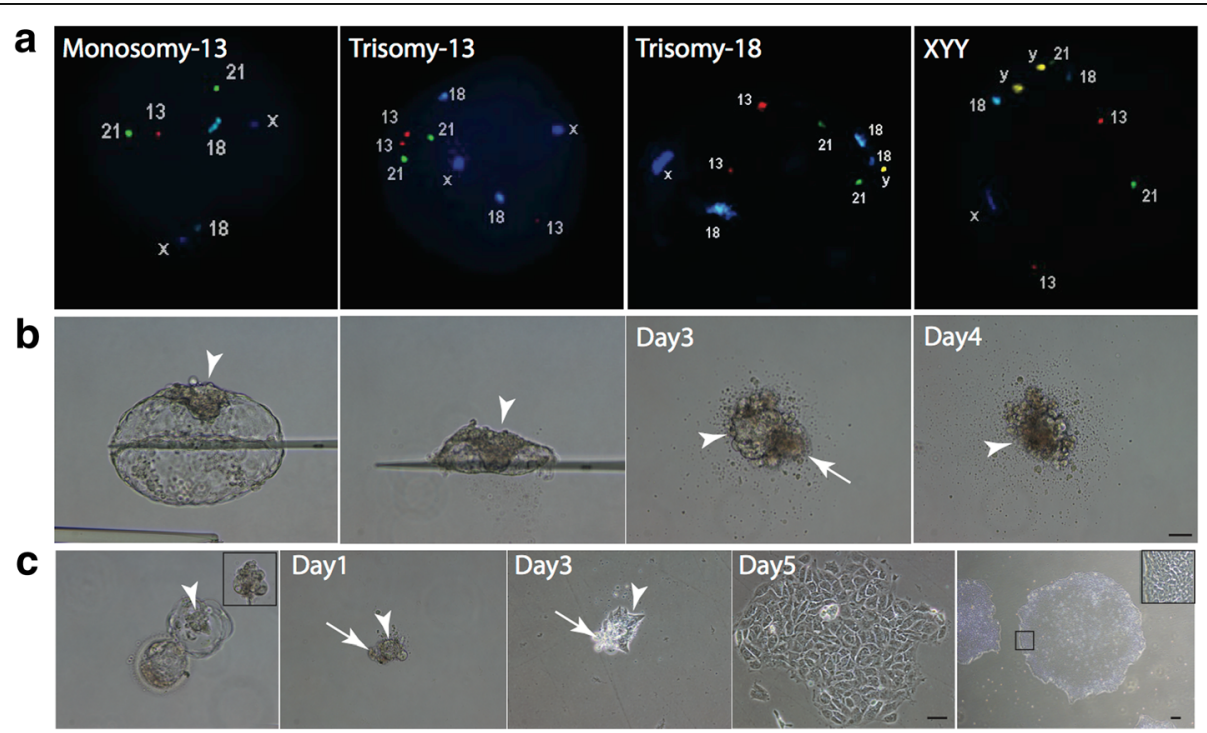

Fig. 3 Derivation of hESCs from aneuploid embryos using MTP under a feeder-free system. a Eight-cell-stage human embryos subjected to blastomere biopsy and their chromosomal abnormalities determined by fluorescence in-situ hybridization (FISH). b Mechanically isolated ICM (arrowheads) with large number of associated TE cells (arrows) detached from Matrigel-coated surface and degenerated after 4 days of culture. c Mechanically isolated ICM (arrowheads) carefully stripped of TE cells (arrows) remains attached to Matrigel-coated surface and continuously proliferated to form large hESC colonies while remaining TE cells degenerated. Scale bar: $50 \mu \mathrm{m}$ 
with a derivation efficiency of $71.4 \%$. Of these five hESC lines, two were derived from monosomy 13 embryos (Si1 and Si2) and one each from XYY embryo (Si3), trisomy 13 embryo (Si4), and parthenogenetic embryo (Si5).

We also used the MTP method to derive hESCs from frozen-thawed embryos. ICMs were isolated from two frozen embryos with 3 pronuclei (3PN) by MID and cultured on Matrigel-coated plates in Nutristem media under hypoxic conditions. One hESC line (Si3PN) was then successfully established with a derivation efficiency of 50\% (Additional file 3: Figure S2A). Karyotyping showed that Si3PN exhibited the 69, XXY karyotype (Additional file 3: Figure S2C). We also successfully used the MTP method to derive hESCs from an embryo with $\mathrm{Hb}$ Bart's hydrops fetalis (SiAtha1) (Additional file 3: Figure S2B). Karyotyping reveals that SiAtha1 exhibited the normal 46, XY karyotype (Additional file 3: Figure S2D).

Taken together, the results show that our MTP method enhanced the hESC derivation efficiency from both normal and abnormal embryos. Using the MTP technique, seven hESC lines were successfully derived from 10 embryos with an overall efficiency of $70 \%$ (Table 2), the highest among other previous reports (Additional file 1: Table S1), and approximately 3-fold higher than the conventional methods, MID and WEC (Table 1, Additional file 1: Table S2). All hESC lines established in this study expressed typical pluripotent marker genes and proteins, and could differentiate to generate derivatives of all three embryonic germ layers both in vitro and in vivo (Additional file 4: Figure S3).

\section{Derivation of $\mathrm{hESC}$ in a feeder-free culture system using minimized TE cell contamination}

To explore use of the MTP method for deriving hESCs under feeder-free conditions, we cultured the ICMs isolated by MID on Matrigel-coated plates throughout the entire culture period without transferring the cells onto HFFs. TE cells deteriorated after 3 days of culture while the ICM remained intact. However, when the culture was continued under this condition, the ICMs began to degenerate and detached from the culture surface on culture day 5 (Fig.
$3 \mathrm{~b})$. When the detached ICMs were transferred onto HFFs for further expansion, they did not proliferate, resulting in the termination of culture.

Based on this observation, it is possible that an extensive deterioration of $\mathrm{TE}$ cells prior to the degeneration of ICMs might release some toxic molecules that exerted deleterious effects on ICM cells. To solve this problem, we tried to minimize the number of contaminated TE cells at the beginning of culture by carefully separating ICMs from the surrounding TE cells in the blastocysts using a fine pulled-glass needle. When those carefully isolated ICMs were cultured on Matrigel-coated plates, they attached to the culture surface and began to proliferate. Using this technique, the numbers of contaminated TE cells in culture were dramatically decreased and the ICM outgrowths proceed even after the remaining TE cells degenerated. After 8 days of culture, the ICM-derived colonies were mechanically dissociated and replated into fresh Matrigel-coated plates. The ICM-derived colonies which exhibited typical hESC morphology (Fig. 3c) could be expanded further and the hESC lines were successfully established. The results demonstrate that an optimized MTP method could be used to derive clinical-grade hESC lines under feederfree and xeno-free medium (Fig. 4).

\section{Discussion}

Previous reports using either the MID or WEC technique to derive hESCs indicated that TE cell outgrowth could suppress ICM expansion and cause them to degenerate, resulting in the low hESC derivation efficiency [30-32]. In the present study, we successfully developed a more effective hESC derivation technique by minimizing the amount of contaminated TE cells during mechanical ICM dissection and using a feeder-free culture system to limit TE cell proliferation (MTP technique). The idea of using the MTP technique is to reduce TE cell proliferation and allow the ICM to expand during the first few days of culture. At this time, the ICM cells begin to acquire the embryonic stem cell phenotype as demonstrated by the upregulation of genes associated with self-renewal,

Table 2 hESC lines successfully derived by MTP technique

\begin{tabular}{llll}
\hline Type of embryo & Number of embryos & Number (\%) of established hESC lines & Name of hESC line \\
\hline Monosomy 13 & 2 & $2(100)$ & $\mathrm{Si}$, Si2 \\
Trisomy 13 & 2 & $1(50)$ & $\mathrm{Si} 4$ \\
$47, \mathrm{XYY}$ & 1 & $1(100)$ & $\mathrm{Si3}$ \\
Parthenogenetic & 1 & $1(100)$ & $\mathrm{Si} 5$ \\
3PN (vitrified-thawed) & 2 & $1(50)$ & $\mathrm{Si3PN}$ \\
Alpha thalassemia & 1 & $1(100)$ & SiAtha1 \\
\hline
\end{tabular}

hESC human embryonic stem cell, MTP minimized trophoblast proliferation 


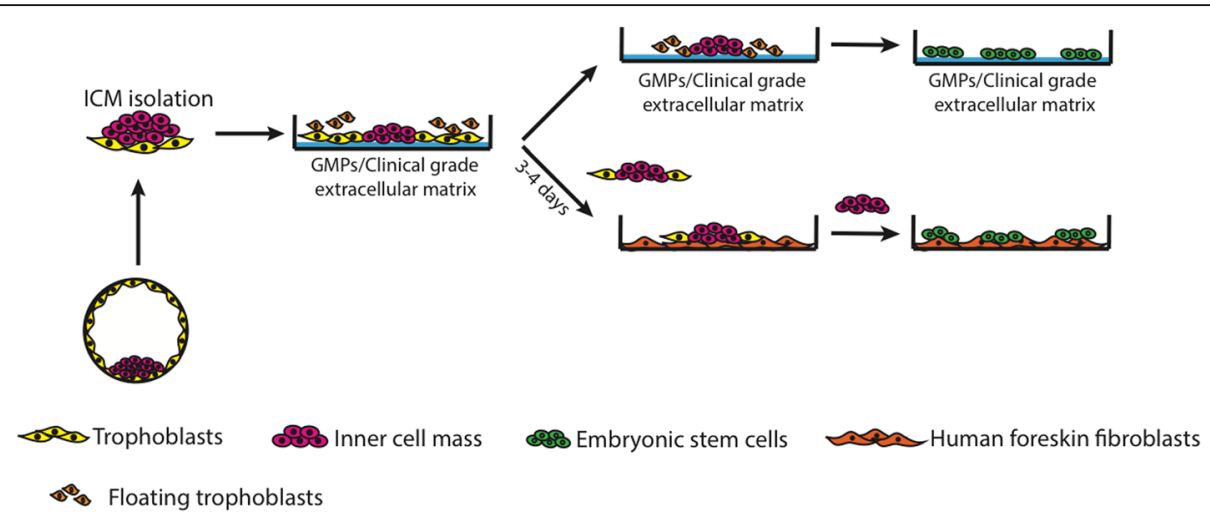

Fig. 4 Derivation of clinical-grade hESCs by MTP under feeder-based and feeder-free conditions. To generate clinical-grade hESCs, mechanically isolated ICM initially cultured on GMP/clinical-grade extracellular matrix, such as rLaminin-521 or CELLstart, for a few days before being transferred onto GMP-grade HFFs (for feeder-based system) or fresh matrix-coated plates (for feeder-free system) to generate hESC colonies. ICM: inner cell mass, GMP: good manufacturing practice

such as Lin28a [33, 34]. It is of importance that the separation of ICM outgrowth from degenerated TE cells is critical for the successful derivation of hESCs under feeder-free conditions. Allowing degenerated TE cells to contact with ICM outgrowth results in ICM degeneration, possibly due to toxic substances or apoptosis signals released from the degenerating TE cells.

The hESC lines derived from various types of embryos using the MTP technique exhibited typical characteristics and functional properties of hESCs, and some lines (Si3PN and SiAtha1) preserved the original genetic mutations of the embryos that were used to derive them. The MTP technique can also be used to derive hESCs under xeno-free conditions, which is suitable for clinical-grade hESC derivation. We also showed that CELLstart, which is a nonanimal GMP-grade extracellular matrix, can be used to derive hESCs by our MTP technique.

In this study, we used human embryos with various chromosomal abnormalities to derive hESCs. Blastomere biopsy was performed when the embryos reached the eight-cell stage for PGD. Those embryos therefore consisted of approximately $12.5-25 \%$ fewer cells than intact embryos [35]. It is controversial whether blastomere biopsy affects embryonic development and the implantation rate. Previous studies demonstrated that blastomere biopsy did not affect blastocyst formation, embryonic implantation, and subsequent development of postimplantation embryos [30-32, 36-41]. However, there were reports suggesting that biopsied embryos showed delayed compaction, generated fewer hatched blastocysts, and had a lower implantation rate (39\%) when compared with nonbiopsied embryos [42-47]. Our results showed that blastomere biopsy did not affect the
hESC derivation efficiency, indicating that the remaining number of blastomeres after biopsy is sufficient for generating ICM for subsequent hESC derivation by the MTP method.

Surprisingly, all hESC lines derived from four embryos with various chromosomal abnormalities exhibited a normal diploid karyotype (Additional file 5: Figure S4). However, this was not unprecedented as there was a report of deriving normal diploid hESCs from aneuploid embryos [48]. This may be due to a phenomenon called "mosaicism" found in small percentages of eight-cell-stage embryos at the time of PGD [49]. The meiotic nondisjunction occurring during germ cell formation and the mitotic nondisjunction occurring during the early cleavage stage of the embryos are mostly responsible for the mosaicism, resulting in affected embryos with both normal diploid cells and aneuploid cells [50-52] (Additional file 6: Figure S5). It is therefore possible that our four abnormal embryos were affected by mosaicism and the normal diploid cells presented in those embryos might outcompete their aneuploid counterparts during the hESC derivation process, resulting in the generation of hESC lines with a normal karyotype (Si1, Si2, $\mathrm{Si} 3$, and $\mathrm{Si} 4$ ).

\section{Conclusion}

We report use of the MTP technique to derive hESCs from normal, disease, frozen, and parthenogenetic embryos with efficiency greater than that described previously. With this MTP technique, hESC lines can be successfully derived under feeder-free conditions in welldefined, xeno-free medium (Fig. 4). This methodology can be used to derive clinical-grade hESCs from a limited number of embryos for future therapeutic applications. 


\section{Additional files}

Additional file 1: Supplement information including supplementary Tables S1-S3. (DOCX 39 kb)

Additional file 2: Figure S1. Detection of a-thalassemia SEA mutation in SiBart1 and SiBart2 hESCs. For a ${ }^{0}$-thalassemia trait (Trait), PCR products of both normal (194 bp) and mutated a-globin gene (570 bp) detected. SiBart1 (Brt1) and SiBart2 (Brt2) hESCs derived from a $a^{0}$-thalassemia embryos only have mutated version of a-globin gene while hESCs derived from normal embryo (Chula2) only have normal version of the gene. (JPG 954 kb)

Additional file 3: Figure S2. Derivation of hESCs from diseased and frozen-thawed embryos using MTP. (A) ICM clump isolated from a frozen-thawed aneuploid 3PN embryo and cultured on Matrigel-coated plate. After culture for 3 days, most TE cells degenerated (arrowhead) while remaining ICM cells were transferred onto fresh HFFs and expanded further to generate hESCs (Si3PN). (B) ICM clump isolated from $\mathrm{Hb}$ Bart's hydrops fetalis embryos and cultured on Matrigel-coated plate. Degenerating TE cells (arrowhead) observed while remaining ICM cells were transferred onto fresh HFFs and expanded further to generate hESCs (SiAtha1). (C) Karyotyping results show Si3PN exhibited a triploid $(69, X X Y)$ karyotype while (D) SiAtha1 exhibited a normal diploid karyotype (46, XY). Scale bar: $50 \mu \mathrm{m}$. (JPG $1215 \mathrm{~kb}$ )

Additional file 4: Figure S3. Characterization of hESC lines derived from MTP. (A) Total transcripts OCT4, SOX2, and NANOG of each hESC line extracted and amplified by PCR using specific primer. PCR product of each transcript from different hESC lines subjected to same agarose gel and same exposure. RT-PCR analysis shows that hESC lines derived from MTP expressed core pluripotent genes, OCT4, NANOG, and SOX2. (B) Immunofluorescent staining shows hESCs derived from MTP expressed typical hESC marker proteins. (C) Spontaneous differentiation of seven hESC cell line-generated derivatives of all three primitive germ layers demonstrated by expression of NESTIN, SMA, and AFP. (D) Hematoxylin and eosin staining of teratoma generated from Si1-Si4 and SiAtra1 showed tissues from three primitive germ layers including endoderm, mesoderm, and ectoderm. Scale bar: $50 \mu \mathrm{m}$. (ZIP 7514 kb)

Additional file 5: Figure S4. Karyotyping analysis of $\mathrm{Si} 1, \mathrm{Si}$, Si3, Si4, and Si5 cell lines exhibited a normal diploid karyotype. (JPG 720 kb)

Additional file 6: Figure S5. Schematic diagram explaining origin of aneuploid chromosome caused by meiotic and mitotic nondisjunction. For meiotic nondisjunction, chromosomal missegregation occurs during meiosis resulting in aneuploid embryos. For mitotic nondisjunction, chromosome missegregation occurs during mitotic cell divisions resulting in mosaicism of normal diploid and aneuploid cells in embryo. For Si3PN, aneuploid chromosome was originated from meiotic nondisjunction, while aneuploid chromosomes of Si1-Si4 likely occurred from mitotic no-disjunction during second or third cell division of the embryos. (JPG $1491 \mathrm{~kb}$ )

\section{Abbreviations}

cDNA: Complementary DNA; GMP: Good manufacturing practice; Hb: Hemoglobin; hESC: Human embryonic stem cell; HFF: Human foreskin fibroblast; ICM: Inner cell mass; iPSC: Induced pluripotent stem cell; IVF: In vitro fertilization; MID: Mechanical ICM dissection; MTP: Minimized trophoblast cell proliferation; Neu5Gc: N-Glycolylneuraminic acid; PBS: Phosphate buffer saline; PGD: Preimplantation genetic diagnosis; RTPCR: Reverse transcription polymerase chain reaction; SEA: Southeast Asia; SIRB: Siriraj Institutional Review Board, Faculty of Medicine, Siriraj Hospital; TE: Trophoblast; WEC: Whole embryo culture; ZP: Zona pellucida

\section{Acknowledgements}

The authors thank Prof. Peter Andrews, Prof. Harry Moore, from The University of Sheffield, Prof. Davor Solter, and Prof. Barbara Knowles for their valuable suggestion during hESC derivation. We would like to thank Dr Kamthorn Pruksananonda and Dr Ruttachuk Rungsiwiwut for kindly providing Chula2 hESCs.

\section{Funding}

This work was supported by The Thailand Research Fund (TRG5780180 to CLa and RTA488-0007 to SI) and the Commission on Higher Education (CHERES-RG-49 to SI). SI is a TRF Senior Research Scholar.

\section{Availability of data and materials}

All datasets in this article are included within the article and additional files.

\section{Authors' contributions}

CLa contributed to conception and design, hESC derivation, the experiment, data analysis and interpretation, financial support, and manuscript writing. PC conducted the experiment and manuscript writing. RC provided blastocyst embryos in this study, and conducted data analysis and interpretation. SP, KS, CK, and OM provided blastocyst embryos in this study. PT contributed to histological analysis. SW contributed to cytogenetic analysis. CLo and PK contributed to data analysis and interpretation, and manuscript writing. YU and PS contributed to data analysis and interpretation. SI contributed to conception and design, financial support, and manuscript writing. All authors read and approved the final manuscript.

\section{Ethics approval and consent to participate}

The study protocol was approved by Siriraj Institutional Review Board, Faculty of Medicine, Siriraj Hospital (SIRB), Mahidol University (Si338/2013). All experiments with human embryos were performed under the guidelines and regulations of SIRB, Mahidol University. The human embryos used in this study were obtained from the infertility unit, Siriraj Hospital. Informed consent was obtained from all couples that donated spare embryos following IVF treatment.

\section{Competing interests}

The authors declare no competing financial interests.

\section{Publisher's Note}

Springer Nature remains neutral with regard to jurisdictional claims in published maps and institutional affiliations.

\section{Author details}

${ }^{1}$ Siriraj Center of Excellence for Stem Cell Research (SiSCR), Faculty of Medicine Siriraj Hospital, Mahidol University, Bangkok 10700, Thailand. ${ }^{2}$ Division of Infertility and Reproductive Biology, Department of Obstetrics and Gynaecology, Faculty of Medicine Siriraj Hospital, Mahidol University, Bangkok 10700, Thailand. ${ }^{3}$ Department of Pathology, Faculty of Medicine Siriraj Hospital, Mahidol University, Bangkok 10700, Thailand. ${ }^{4}$ Division of Medical Genetics, Department of Obstetrics and Gynaecology, Faculty of Medicine Siriraj Hospital, Mahidol University, Bangkok 10700, Thailand. ${ }^{5}$ Division of Hematology, Department of Medicine, Faculty of Medicine Siriraj Hospital, Mahidol University, Bangkok 10700, Thailand. ${ }^{6}$ Division of Cell Biology, Faculty of Medicine, Thammasat University, Pathumthani 12120, Thailand.

Received: 7 February 2018 Revised: 28 March 2018 Accepted: 11 April 2018 Published online: 11 May 2018

\section{References}

1. Thomson JA, Itskovitz-Eldor J, Shapiro SS, Waknitz MA, Swiergiel JJ, Marshall VS, et al. Embryonic stem cell lines derived from human blastocysts. Science (New York, NY). 1998;282(5391):1145-7.

2. Chen AE, Egli D, Niakan K, Deng J, Akutsu H, Yamaki M, et al. Optimal timing of inner cell mass isolation increases the efficiency of human embryonic stem cell derivation and allows generation of sibling cell lines. Cell Stem Cell. 2009;4(2):103-6.

3. Strom S, Holm F, Bergstrom R, Stromberg AM, Hovatta O. Derivation of 30 human embryonic stem cell lines_improving the quality. In Vitro Cell Dev Biol Anim. 2010;46(3-4):337-44

4. Solter D, Knowles BB. Immunosurgery of mouse blastocyst. Proc Natl Acad Sci U S A. 1975;72(12):5099-102.

5. Stojkovic M, Lako M, Stojkovic P, Stewart R, Przyborski S, Armstrong $L$, et al. Derivation of human embryonic stem cells from day-8 blastocysts recovered after three-step in vitro culture. Stem Cells. 2004;22(5):790-7.

6. Klimanskaya I, Chung Y, Meisner L, Johnson J, West MD, Lanza R. Human embryonic stem cells derived without feeder cells. Lancet (London, England). 2005;365(9471):1636-41.

7. Tannenbaum SE, Turetsky $\Pi$, Singer O, Aizenman E, Kirshberg S, Ilouz $\mathrm{N}$, et al. Derivation of xeno-free and GMP-grade human embryonic stem cells_platforms for future clinical applications. PLoS One. 2012; 7(6):e35325. 
8. Strom S, Inzunza J, Grinnemo KH, Holmberg K, Matilainen E, Stromberg $A M$, et al. Mechanical isolation of the inner cell mass is effective in derivation of new human embryonic stem cell lines. Hum Reprod. 2007; 22(12):3051-8

9. Fan $Y$, Luo $Y$, Chen $X$, Sun $X$. A modified culture medium increases blastocyst formation and the efficiency of human embryonic stem cell derivation from poor-quality embryos. J Reprod Dev. 2010;56(5):533-9.

10. Wang Q, Fang ZF, Jin F, Lu Y, Gai H, Sheng HZ. Derivation and growing human embryonic stem cells on feeders derived from themselves. Stem Cells. 2005;23(9):1221-7.

11. Oh SK, Kim HS, Ahn HJ, Seol HW, Kim YY, Park YB, et al. Derivation and characterization of new human embryonic stem cell lines: SNUhES1, SNUhES2, and SNUhES3. Stem Cells. 2005:23(2):211-9.

12. Simon C, Escobedo C, Valbuena D, Genbacev O, Galan A, Krtolica A, et al. First derivation in Spain of human embryonic stem cell lines: use of long-term cryopreserved embryos and animal-free conditions. Fertil Steril. 2005;83(1):246-9.

13. Faden RR, Dawson L, Bateman-House AS, Agnew DM, Bok H, Brock DW, et al. Public stem cell banks: considerations of justice in stem cell research and therapy. Hast Cent Rep. 2003;33(6):13-27.

14. Crook JM, Peura TT, Kravets L, Bosman AG, Buzzard JJ, Horne R, et al. The generation of six clinical-grade human embryonic stem cell lines. Cell stem cell. 2007;1(5):490-4.

15. Kim SJ, Lee JE, Park JH, Lee JB, Kim JM, Yoon BS, et al. Efficient derivation of new human embryonic stem cell lines. Mol Cells. 2005;19(1):46-53.

16. Cowan CA, Klimanskaya I, McMahon J, Atienza J, Witmyer J, Zucker JP, et al. Derivation of embryonic stem-cell lines from human blastocysts. N Engl J Med. 2004;350(13):1353-6.

17. Takahashi K, Yamanaka S. Induction of pluripotent stem cells from mouse embryonic and adult fibroblast cultures by defined factors. Cell. 2006;126(4):663-76.

18. Garitaonandia I, Amir H, Boscolo FS, Wambua GK, Schultheisz HL, Sabatini K et al. Increased risk of genetic and epigenetic instability in human embryonic stem cells associated with specific culture conditions. PLoS One. 2015;10(2):e0118307.

19. Na J, Baker D, Zhang J, Andrews PW, Barbaric I. Aneuploidy in pluripotent stem cells and implications for cancerous transformation. Protein Cell. 2014; 5(8):569-79.

20. Feng Q, Lu SJ, Klimanskaya I, Gomes I, Kim D, Chung Y, et al. Hemangioblastic derivatives from human induced pluripotent stem cells exhibit limited expansion and early senescence. Stem Cells. 2010;28(4):704-12.

21. Hu BY, Weick JP, Yu J, Ma LX, Zhang XQ, Thomson JA, et al. Neural differentiation of human induced pluripotent stem cells follows developmental principles but with variable potency. Proc Natl Acad Sci U S A. 2010;107(9):4335-40.

22. Chin MH, Mason MJ, Xie W, Volinia S, Singer M, Peterson C, et al. Induced pluripotent stem cells and embryonic stem cells are distinguished by gene expression signatures. Cell Stem Cell. 2009;5(1):111-23.

23. Kang E, Wang X, Tippner-Hedges $R$, Ma H, Folmes CD, Gutierrez NM, et al. Age-related accumulation of somatic mitochondrial DNA mutations in adult-derived human iPSCs. Cell Stem Cell. 2016;18(5): 625-36.

24. Bouma MJ, van Iterson $M$, Janssen $B$, Mummery $C L$, Salvatori DCF, Freund C. Differentiation-defective human induced pluripotent stem cells reveal strengths and limitations of the teratoma assay and in vitro pluripotency assays. Stem Cell Rep. 2017:8(5):1340-53.

25. Simonson OE, Domogatskaya A, Volchkov P, Rodin S. The safety of human pluripotent stem cells in clinical treatment. Ann Med. 2015;47(5): 370-80.

26. Nori S, Okada Y, Nishimura S, Sasaki T, Itakura G, Kobayashi Y, et al. Longterm safety issues of iPSC-based cell therapy in a spinal cord injury model: oncogenic transformation with epithelial-mesenchymal transition. Stem Cell Rep. 2015;4(3):360-73.

27. Tesarova L, Simara P, Stejskal S, Koutna I. The aberrant DNA methylation profile of human induced pluripotent stem cells is connected to the reprogramming process and is normalized during in vitro culture. PLoS One. 2016;11(6):e0157974.

28. El Khatib MM, Ohmine S, Jacobus EJ, Tonne JM, Morsy SG, Holditch SJ, et al. Tumor-free transplantation of patient-derived induced pluripotent stem cell progeny for customized islet regeneration. Stem Cells Transl Med. 2016;5(5):694-702.
29. Winichagoon P, Fucharoen S, Kanokpongsakdi S, Fukumaki Y. Detection of alpha-thalassemia-1 (Southeast Asian type) and its application for prenatal diagnosis. Clin Genet. 1995;47(6):318-20.

30. Monk M, Handyside AH. Sexing of preimplantation mouse embryos by measurement of $X$-linked gene dosage in a single blastomere. J Reprod Fertil. 1988;82(1):365-8.

31. Wilton LJ, Shaw JM, Trounson AO. Successful single-cell biopsy and cryopreservation of preimplantation mouse embryos. Fertil Steril. 1989; 51(3):513-7.

32. Hardy $\mathrm{K}$, Martin $\mathrm{KL}$, Leese HJ, Winston RM, Handyside AH. Human preimplantation development in vitro is not adversely affected by biopsy at the 8-cell stage. Hum Reprod. 1990;5(6):708-14.

33. Tang F, Barbacioru C, Bao S, Lee C, Nordman E, Wang X, et al. Tracing the derivation of embryonic stem cells from the inner cell mass by single-cell RNA-Seq analysis. Cell Stem Cell. 2010;6(5):468-78.

34. Nichols J, Smith A. The origin and identity of embryonic stem cells. Development. 2011:138(1):3-8

35. McArthur SJ, Leigh D, Marshall JT, de Boer KA, Jansen RP. Pregnancies and live births after trophectoderm biopsy and preimplantation genetic testing of human blastocysts. Fertil Steril. 2005;84(6):1628-36

36. Cohen J, Wells D, Munne S. Removal of 2 cells from cleavage stage embryos is likely to reduce the efficacy of chromosomal tests that are used to enhance implantation rates. Fertil Steril. 2007;87(3):496-503.

37. Cieslak-Janzen J, Tur-Kaspa I, Ilkevitch Y, Bernal A, Morris R, Verlinsky Y Multiple micromanipulations for preimplantation genetic diagnosis do not affect embryo development to the blastocyst stage. Fertil Steril. 2006;85(6):1826-9.

38. Liu Y, Zhou C, Xu Y, Fang C, Zhang M. Pregnancy outcome in preimplantation genetic diagnosis cycle by blastomere biopsy is related to both quality and quantity of embryos on day 3. Fertil Steril. 2009;91(4 Suppl):1355-7.

39. Xu K, Montag M. New perspectives on embryo biopsy: not how, but when and why? Semin Reprod Med. 2012;30(4):259-66.

40. Sampino S, Zacchini F, Swiergiel AH, Modlinski AJ, Loi P, Ptak GE. Effects of blastomere biopsy on post-natal growth and behavior in mice. Hum Reprod. 2014;29(9):1875-83.

41. Ishii T. Reproductive medicine involving genome editing: clinical uncertainties and embryological needs. Reproductive biomedicine online. 2017;34:27-31. https://doi.org/10.1016/j.rbmo.2016.09.009.

42. Kirkegaard K, Hindkjaer JJ, Ingerslev HJ. Human embryonic development after blastomere removal: a time-lapse analysis. Hum Reprod. 2012;27(1):97-105

43. Bar-El L, Kalma Y, Malcov M, Schwartz T, Raviv S, Cohen T, et al. Blastomere biopsy for PGD delays embryo compaction and blastulation: a time-lapse microscopic analysis. J Assist Reprod Genet. 2016;33(11):1449-57.

44. Staessen C, Verpoest W, Donoso P, Haentjens P, Van der Elst J, Liebaers I, et al. Preimplantation genetic screening does not improve delivery rate in women under the age of 36 following single-embryo transfer. Hum Reprod. 2008:23(12):2818-25

45. Debrock S, Melotte C, Spiessens C, Peeraer K, Vanneste E, Meeuwis L, et al. Preimplantation genetic screening for aneuploidy of embryos after in vitro fertilization in women aged at least 35 years: a prospective randomized trial. Fertil Steril. 2010;93(2):364-73.

46. Scott RT Jr, Upham KM, Forman EJ, Zhao T, Treff NR. Cleavage-stage biopsy significantly impairs human embryonic implantation potential while blastocyst biopsy does not: a randomized and paired clinical trial. Fertil Steril. 2013;100(3):624-30.

47. Hardarson T, Hanson C, Lundin K, Hillensjo T, Nilsson L, Stevic J, et al. Preimplantation genetic screening in women of advanced maternal age caused a decrease in clinical pregnancy rate: a randomized controlled trial. Hum Reprod. 2008;23(12):2806-12.

48. Lavon N, Narwani K, Golan-Lev T, Buehler N, Hill D, Benvenisty N. Derivation of euploid human embryonic stem cells from aneuploid embryos. Stem Cells. 2008;26(7):1874-82.

49. Ravichandran K, Guzman L, Escudero T, Zheng X, Colls P, Jordan A, et al. Causes and estimated incidences of sex-chromosome misdiagnosis in preimplantation genetic diagnosis of aneuploidy. Reprod BioMed Online. 2016:33(5):550-9.

50. Vanneste $E$, Voet T, Le Caignec C, Ampe M, Konings P, Melotte C, et al. Chromosome instability is common in human cleavage-stage embryos. Nat Med. 2009;15(5):577-83. 
51. Biancotti JC, Narwani K, Buehler N, Mandefro B, Golan-Lev T, Yanuka O, et al. Human embryonic stem cells as models for aneuploid chromosomal syndromes. Stem Cells. 2010;28(9):1530-40.

52. Yuan L, Liu JG, Hoja MR, Wilbertz J, Nordqvist K, Hoog C. Female germ cell aneuploidy and embryo death in mice lacking the meiosis-specific protein SCP3. Science (New York, NY). 2002;296(5570):1115-8.

Ready to submit your research? Choose BMC and benefit from:

- fast, convenient online submission

- thorough peer review by experienced researchers in your field

- rapid publication on acceptance

- support for research data, including large and complex data types

- gold Open Access which fosters wider collaboration and increased citations

- maximum visibility for your research: over $100 \mathrm{M}$ website views per year 